\title{
Survival of implementation TENS electric currents for glycemic control in type 2 diabetic patients out of control, captured in the CERTF (rehabilitation school clinic \& physical therapy)
}

\section{Pervivencia de implementación de corrientes eléctricas TENS para el control de glicemia en pacientes diabéticos tipo 2 descontrolados, captados en la CERTF (Clínica Escuela de Rehabilitación y Terapia Física)}

\author{
LÓPEZ-MORALES, Guadalupe $\dagger^{*}$, VALENCIA-MELO, Stephany, LIRA-FUENTES, Nelly and \\ PATRICIO-RAFAEL, Emmanuel
}

ID $1^{\text {st }}$ Author: Guadalupe, López-Morales

ID $1^{\text {st }}$ Coauthor: Stephany, Valencia -Melo

ID $2^{\text {nd }}$ Coauthor: Nelly, Lira-Fuentes

ID $3^{\text {rd }}$ Coauthor: Emmanuel, Patricio-Rafael

DOI: $10.35429 / J E H W .2020 .7 .4 .7 .12$

Received July 15, 2020; Accepted December 30, 2020

\begin{abstract}
Diabetes Mellitus (DM) represents a health challenge, due to its high prevalence and the morbidity that it entails, but because of the costs that its treatment implies. Diabetes Mellitus is a chronic-degenerative disease characterized by defects in the action and / or production of insulin, which generates a hyperglycemic effect.The objective in the application of TENS is to decrease the glycated hemoglobin value by one percentage point with respect to its initial value through the application of external electrical currents TENS in uncontrolled type II diabetic patients. Electrostimulation is considered an alternative for the treatment of uncontrolled Type 2 Diabetes Mellitus, since it produces a temporary, metabolic, morphological transformation of fast fibers or slow muscle fibers. With this, glucose metabolism can be controlled by its plasma concentrations and by a large extent of glucose transport through the cell membrane, thus being a treatment option that does not generate side effects for the patient, and does not generate high costs in your application.
\end{abstract}

Uncontrolled Type 2 Diabetes Mellitus, TENS, HbA1c

\begin{abstract}
Resumen
La Diabetes Mellitus (DM) representa un reto para la salud, por su alta prevalencia y la morbilidad que conlleva, sino por los costos que implica su tratamiento. La Diabetes Mellitus es una enfermedad crónico-degenerativa que se caracteriza por defectos en la acción y/o producción de insulina, lo que genera un efecto hiperglicemiante. El Objetivo en la aplicación de TENS es disminuir en un punto porcentual el valor de hemoglobina glucosilada con respecto a su valor inicial a través de la aplicación de corrientes eléctricas externas TENS en pacientes diabéticos tipo II descontrolados. La electroestimulación es considerada una alterantiva para el tratamiento de la Diabetes Mellitus tipo 2 descontrolada, ya que produce una transformación temporal, metabólica, morfológica, de fibras rápidas o fibras musculares lentas. Con esto el metabolismo de la glucosa puede ser controlada por sus concentraciones plasmáticas y por una gran extensión del transporte de glucosa a través de la membrana celular, siendo así una opción de tratamiento que no genera efectos secundarios al paciente, y no genera costos elevados en su aplicación.
\end{abstract}

Diabetes Mellitus tipo 2 descontrolada, TENS, HbA1c

Citation: LÓPEZ-MORALES, Guadalupe, VALENCIA-MELO, Stephany, LIRA-FUENTES, Nelly and PATRICIORAFAEL, Emmanuel. Survival of implementation TENS electric currents for glycemic control in type 2 diabetic patients out of control, captured in the CERTF (rehabilitation school clinic \& physical therapy). Journal-Health Education and Welfare. 2020. 4-7:7-12.

\footnotetext{
* Correspondence to Author (Email: guadalupe.lopez@utxicotepec.edu.mx).

$\dagger$ Researcher contributing as first author.
} 


\section{Introduction}

According to the World Health Organization (WHO), Diabetes Mellitus is one of the most common and dangerous diseases in Mexico, which is the second cause of mortality in all ages, reporting 87 thousand deaths in 2014 in a population over thirty years of age, derived from complications including diabetic neuropathy, diabetic foot, ulcers, amputations, diabetic retinopathy and kidney failure.

The Mexican Institute of Social Security (IMSS) reports for the Puebla delegation more than 4 thousand deaths per year from diabetes mellitus. It is therefore necessary to generate new techniques that allow better glycemic control to be carried out, which reduces the complications of type 2 diabetes mellitus, producing an impact on the intake of hypoglycemic drugs and their effects.

TENS is a type of electrotherapy that since its appearance in the field of Physical Therapy has been used as a successful modality in the attenuation of acute and chronic pain as well as being a non-invasive and painless technique; Although they are still being investigated, it is intended to demonstrate its metabolic effects with neuromuscular activation.

The School of Rehabilitation and Physical Therapy Clinic (CERTF) belonging to the Technological University of Xicotepec de Juárez provides care to the general public with different pathologies such as type 2 diabetes mellitus, therefore the importance of proposing and establishing intervention alternatives for patients diabetics, which contribute to their rehabilitation and glycemic control.

\section{Justification}

Diabetes Mellitus (DM) presents extraordinary challenges for health systems, not only because of its high prevalence and the mobility it entails, but also because of the complexity and costs involved in its treatment.

It is estimated that about $8.3 \%$ of the world's adult population has DM (about 366 million). This will increase to about 9.9\% (552 million) by the year 20301. According to WHO data, $80 \%$ of deaths from DM occur in low- and middle-income countries ${ }^{2}$.
The measurement of glycated hemoglobin is the standard criterion for the evaluation of glycemic control, which seeks to reduce or delay the appearance of micro and macrovascular complications, for this reason it is important to look for the control of percentage figures of glycemia ${ }^{3}$.

\section{General purpose}

Identify the parameters to decrease the glycated hemoglobin value by one percentage point with respect to its initial value through the application of external electrical currents TENS in uncontrolled type II diabetic patients.

\section{Specific objectives}

Know the management of glycemic indices in diabetic patients, through physiotherapeutic intervention.

Propose a treatment protocol with TENS current that reduces the consumption of hypoglycemic agents.

\section{Theoretical framework}

\section{Background}

Glycogen is the main storage carbohydrate in animals; corresponds to starch in vegetables; It is a branched polymer of $\alpha$-d-glucose found primarily in the liver and muscles.

In studies applied in rats, it was observed that "the greater the decrease in muscle glycogen after exercise, fasting, electrostimulation or a low-carbohydrate diet, the GLUT4 concentration found in the sarcolemma was higher, and therefore greater glucose uptake after exercise. food intake "4.

In March 2015, an article was published on the effects of a comprehensive electrostimulation program in people with type 2 diabetes. The intervention consisted of 20minute training sessions for 15 subjects with an average age of 61.7 years, twice a week. for 10 weeks 5. The authors conclude that fasting blood glucose decreased significantly, as well as the HbA1c level, they mention that Comprehensive Electrostimulation (EMS) may be a new method to help patients overcome their lifestyle. 
Furthermore, it was found that after the application of EMS currents in the muscles of the trunk, legs and arms, there was an improvement in glucose metabolism and functional performance in patients with DM2.

Another advantage of electrostimulation is that it can be an effective strategy to attenuate the loss of muscle mass, since these patients normally present an exacerbated sarcolemma, in a study carried out in six 70-year-old men with type 2 diabetes mellitus, it was concluded that Neuromuscular Electrical Stimulation (NMES) directly stimulate skeletal muscle protein synthesis rates in vivo in humans6.

It is important to consider case studies such as the one presented by MUEEN-ULLAN, Khan in 2012 in the Singapore Medicine journal: an 80-year-old man with type 2 diabetes mellitus came to the hospital with back pain, and a session was recommended of TENS (transcutaneous nerve electrostimulation) every 24 hours. When the improvement was observed, the dose was increased to 3 times every 24 hours, as a side effect the man suffered hypoglycemia, opposite effect when suppressing the treatment with TENS hyperglycemia was produced, but when restarting it again the response was hypoglycemic7. The authors' conclusions are aimed at explaining these episodes by effective pain control, decreased sympathetic stimulation, increased insulin sensitivity, or altered muscle metabolism.

\section{Diabetes Mellitus II}

Diabetes Mellitus is a chronic degenerative disease characterized by defects in the action and / or production of insulin, which generates a hyperglycemic effect. It is related to the condition of obesity and secondary to insulin resistance in conjunction with the deterioration of the B cell function of the pancreas, producing the ability to maintain glycemic concentrations, which leads to hyperglycemia, initially in post-prandial states. and then preprandial giving origin to the diagnosis of Diabetes Mellitus.
Diabetes Mellitus is related to obesity, therefore, the accumulated fatty tissue in adipocytes seems to initiate the pathophysiological process, adipocytes accumulate fatty acids in the form of triglycerides and adipokine signals, the adipocyte has the characteristic of changing its size according to the fatty acids that accumulate, fatty acids that fail to be stored in adipocytes tend to accumulate in skeletal muscle tissue and the liver, to which it is important to mention that skeletal muscle is the main target organ of insulin since it deposits the $80 \%$ of circulating glucose, the arrival of fatty acids blocks insulin signals, generating insulin resistance in skeletal muscle.

Damage to the B cell of the pancreas is related to genetic factors related to oxidative stress (glycogenolysis, B oxidation), decreasing transcription factors in the duodenum and pancreas, generating lipotoxicity.

The alteration in glucose transport is due to defects in the signaling pathway, this produces a deficient translocation of intracytoplasmic GLUT 4 of the cell membrane. GLUT4 is located in the cytoplasm stored in the form of vesicles, the translocation of GLUT4 vesicles or insulin response vesicles from the cytoplasm to the plasma membrane, is regulated by the action of insulin, as the GLUT4 vesicle of the cytoplasm translocates to the membrane, with subsequent glucose uptake, translocation is influenced by serine / threonine phosphatadylinositol3 kinase (AKT).

The deposition of diacylglycerol and ceramides in skeletal muscle alters the translocation of GLUT4, causing an inflammatory process that leads to insulin resistance present in Diabetes Mellitus, studies have shown that GLUT4 deficiency produces alterations in signaling in muscle and liver, decreasing the phosphorylation activity on the insulin receptor substrate.

\section{Classification of Diabetes Mellitus}

Gestational diabetes: it is the alteration in the metabolism of carbohydrates that is detected for the first time during pregnancy, this translates an insufficient adaptation to the insulin resistance that occurs in the pregnant woman. 
Type 1 diabetes mellitus. There is destruction of beta cells of the pancreas, generally with absolute insulin deficiency. Patients can be of any age, almost always lean, and usually have an abrupt onset of signs and symptoms with insulinopenia before the age of 30 years.

Type 2 diabetes mellitus. It is manifested by insulin resistance and concomitantly a deficiency in its production, it can be absolute or relative. Patients are usually older than 30 years when the diagnosis is made, they are obese and have relatively few classic symptoms (Roberto de Jesús Sandoval Muñiz, 2016).

\section{Other types of Diabetes.}

For genetic causes.

Autoimmune.

Medications. Mellitus:

Criteria for the Diagnosis of Diabetes

Fasting blood glucose greater than 125 $\mathrm{mg} / \mathrm{dL}$. Fasting of at least 8 hours.

2h PG greater than $200 \mathrm{mg} / \mathrm{dL}$ in PTG test with $75 \mathrm{~g}$.

A1c of $6.5 \%$ or more.

HbA1c> 210-240 mg / dL.

With this, it is understood that the uncontrolled diabetic is one who is above these figures.

\section{Transcutaneous Electrostimulation (TENS)}

\section{Neuromuscular}

TENS currents are a specialized form of electrical stimulation, designed to reduce pain. The pulses of the electrical currents can be square, rectangular or spiculated, conventional TENS is the most used in the practical field, it is highly effective in acute pain, in root syndromes, among other indications.
For conventional stimulation it is normally between 30 and 60 minutes, the application time is shorter (20 to $30 \mathrm{~min}$ ) in the forms of motor stimulation for which tolerance is lower.

Electrical stimulation reverses this recruitment pattern, which is carried out from the fibers that are usually located more superficially, corresponding to large motor neurons that innervate the fast muscle fiber. Voluntary contractions do not produce muscle fatigue as early in the exercise period as induced electrical contractions do.

Each time the electrical stimulus is applied, the same motor units respond. Voluntary muscle contraction varies from one movement to another because some motor units are excited while others are inactive. However, this contractile synchrony can be favorable to train the muscles through the use of synchronized contractions that improve muscle strength and work.

Neuromuscular electrostimulation (NMES) has returned its interest in enhancing the healthy innervated muscle. It is a proven fact that NMES is effective in increasing muscle strength and increasing local circulation in contracted muscle.

Prolonged electrostimulation (more than 3 weeks) of low amplitude and high number of repetitions (series of 10 contractions) produces an increase in resistance and biochemical modifications in the muscle: increase in oxidative activity, myoglobin, mitochondria and the number of capillaries. That is, there is a temporary, metabolic and even morphological transformation of fast fibers or slow muscle fibers.

\section{Physiology of muscle contraction}

Muscle contraction is a highly regulated process, which depends on the concentration of free $\mathrm{Ca} 2+$ in the cytoplasm $([\mathrm{Ca} 2+]$ and that in skeletal muscle is regulated primarily by the sarcoplasmic reticulum (SR) which functions as a store of high concentrations of $\mathrm{Ca} 2+(0.5$ to 2 $\mathrm{mM}$ ) since it participates as a calcium store as well as its participation in the regulation of the coupling-excitation-contraction process. 
Muscle contraction is the result of the molecular interaction that occurs between (actin and myosin) in which the excitation-contraction sequence is activated in the muscle that is initiated by the propagation of an action potential along the plasma membrane and $\mathrm{T}$ tubules which detect changes in the membrane potential by the DHPR dihydropyridine receptors that activate the sarcoplasmic reticulum (RS) which when activated increases Ca concentrations in the cytoplasm and thus the activation of contractile filaments (actin and myosin) the power shock or contraction occurs.

Muscle contraction is a process activated by a nerve-type electrical stimulus that causes shortening of muscle fibers, this is displaced by motor neurons. In that sense, mention that the muscular work of 2 seconds needs a cellular deposit of $100 \mathrm{mmol}$, which corresponds to 4 kilojoules or kilocalories.

\section{Argumentation}

Based on the information collected within the physiotherapeutic modalities, TENS is a proposal for the control of glycemic indices in type 2 diabetic patients, since during its application there is a decrease in glucose through the muscular contraction generated by the electrical stimulus.

In the publication made by Khan in 2012 which is named: Does the application of TENS have a role in the control of diabetes mellitus in insulin-dependent patients? The effects of TENS in pain control were demonstrated, secondary to this it generated a hypoglycemic effect. (MUEEN-ULLAN, Khan)

Therefore, it is considered feasible to continue the studies of TENS and its effects in patients with uncontrolled type 2 diabetes mellitus, hoping to obtain favorable results in future applications.

\section{Conclusion}

Glucose metabolism can be controlled by its plasma concentrations and by a large extent of glucose transport across the cell membrane.
Because of their ability to generate muscle contractions and have few risks in their application, TENS is feasible to use in uncontrolled type 2 diabetic patients who attend the CERTF and thus propose a treatment strategy to lower their glycemic indices as well as the costs of Attention.

\section{References}

Whiting DR, Guariguata L, Weil C, Shaw J. (2011) IDF diabetes atlas: global estimates of the prevalence of diabetes for 2011 and 2030. Diabetes Res Clin Pract; 94 (3): 311-21.

World Health Organization. (2020) Media Centre, Fact Sheet. Diabetes. Disponible en: http://www.who.int/mediacentre/factsheets/fs31 2/en/index.html.

Spellman CW. (2007). Insulin therapy for maximal glycemic control in type 2 diabetes mellitus. J Am Osteopath Assoc; 107 (7): 2609.

Ramos Jimenez, (2009).Efectos del ejercicio sobre los mecanismos celulares para la capatación de glucosa en el músculo esqueletico. REB 28(4):130-139.

Van Buuren et al. (2015). Electrical Myostimulation (EMS) Improves Glucose Metabolism and Oxygen Uptake in Type 2 Diabetes Mellitus Patients-Results from the EMS Study. Diabetes TechnolTher. DOI: 10.1089/DIA.2014.0315.

Wall et al. (2012). Neuromuscular electrical stimulation increases muscle proteinsyntesis in elderly type 2 diabetic men. Am J Physio EndrocrinoMetab; 303(5): E614-23.

Mueen Ullan Khan (2012). ¿Tiene algún papel la aplicación de la TENS en el control de la diabetes mellitus en pacientes insulinodependientes?; 53(11):e249-50.

Consejo de Salubridad General. (2014). Tratamiento de la Diabetes Mellitus tipo 2 en el primer nivel de atención. Guía de práctica clínica, 139.

Despaigne, C. O. (2015). Hemoglobina glucosilada en pacientes con diabetes mellitus. MEDISAN, 19. 
Roberto de Jesús Sandoval Muñiz, B. V. (2016). Glucotransportes (GLUT): Aspectos Clínicos, moleculares y genéticos. Gaceta Médica de México, Martín Cordero, Jorge (2008). Agentes físicos Terapeuticos. Ciencias Medicas. Págs.:304-308

Medicina de Rehabilitación BIOMECÁNICA(1999). Sobre la fisiología de la contracción. Recuperado de sitio web: http://www.sld.cu/sitios/rehabilitacionbio/buscar.php?id=20619\&iduser=4\&id_topic $=$ 17 